\title{
CONCERNING THE TEMPERATURE OF THE NERNST LAMP.
}

By Leon W. Hartman.

$\mathrm{T}^{\mathrm{H}}$ $\mathrm{HE}$ early determinations of the temperature of the incandescent glower of the Nernst lamp gave values which were undoubtedly much too high. These determinations were based on the law of the radiation from a black body. To this class of radiators, however, the Nernst glower does not belong; so that if the glower emits selective radiation as compared with the radiation from a black body, its measured black body temperature might be much above its actual temperature. This is the case; hence the higher values of its temperature, as found by the early investigators, is explained.

If one avails himself of existing data and methods and applies the data and curves of $\AA$ Angström ${ }^{1}$ to the data of the writer, ${ }^{2}$ published in a former number of this journal, a value of the temperature much lower than that cited by Lummer and Pringsheim ${ }^{3}$ will be obtained. This discrepancy then makes a determination of the temperature of the incandescent glower by direct measurement very desirable.

When the data for the energy losses from incandescent platinum wires in air had been obtained, ${ }^{4}$ an effort was made by the writer to utilize the same method for determining the temperature of the incandescent glower of the Nernst lamp. Briefly stated, this method was as follows: The candle power per unit length for varying power supply was first determined with a number of Nernst glowers. In front of an iridium furnace containing a piece of magnesium oxide, was then mounted a frame for the glowers, in series with which was a suitable regulating rheostat. When the furnace was heated, the magnesium within was heated up to incandescence.

1 Ångström, Phys. Rev., I7, p. 302, 1903.

${ }^{2}$ Hartman, Phys. Rev., 17, p. 65, 1903.

${ }^{3}$ Lummer and Pringsheim, Verhd. d. Deutsch. Ges., 3, p. 36, rgor.

${ }^{4}$ Hartman, Phys. Zeitschr. 5, p. 579, 1904. 
[Vol. XXII.

Each glower in turn was then mounted on the frame and heated by a current until its color, as seen against the magnesium oxide as a background, seemed as near the color of the latter as it was possible to get it. Noting the power supply, the candle power per centimeter length could be determined from the plotted curves of the first set of observations. As soon as the power supplied was determined, the temperature of the interior of the furnace, $i$. e., the temperature of the magnesium oxide was measured by means of a Wanner pyrometer. Some of the data thus obtained are given in the upper part of the following table.

TABLE I.

Measured Energy Supplied.

\begin{tabular}{r|c|c|c|c|c|c|c|c}
\hline No. & Amp. & Volts. & Watts. & $\frac{\text { Watts }}{\text { cm. }}$ & $\begin{array}{c}\text { Tempr. } \\
\text { (abs. }\end{array}$ & $\frac{\text { Watts }}{\mathrm{cm.}}$ & C. P. & $\frac{\text { C. P. }}{\mathrm{mm.}^{2}}$ \\
\hline I. & 0.148 & 173 & 25.6 & 16.3 & $2,360^{\circ}$ & 1.79 & 14.8 & 3.25 \\
II. & 0.410 & 182 & 74.6 & 36.1 & 2,360 & 1.83 & 42.0 & 3.29 \\
III. & 0.846 & 175 & 148.0 & 52.9 & 2,360 & 1.75 & 86.8 & 3.22 \\
IV. & 0.810 & 103 & 83.5 & 59.6 & 1,800 & 1.90 & 47.0 & 3.36 \\
\hline
\end{tabular}

In obtaining these data the writer had the coöperation and assistance of Professor Nernst and one of his assistants, but at that time some doubt arose as to the accuracy of the temperature determinations thus made, and they have not been published hitherto. The writer has since decided to make some independent temperature measurements following an entirely different method, the details of which are given below.

When Professor E. L. Nichols made his observations for the determination of the temperature of the acetylene flame, ${ }^{1}$ it was the writer's privilege to assist in a small way. It seemed probable, therefore, that the same method used in those former measurements might be used to good advantage in determining the actual temperature of the incandescent glower when the latter was carrying a given constant load. Three specimens of the same platinum and platinumrhodium wire used in the determinations just mentioned were therefore taken, pulled down to suitable size, and made into thermoelements. After a I Io-volt glower with its ballast had been mounted on a suitable frame and connected in series with an ad-

1 Nichols, Phys. Rev., ro, p. 234, I9oo. 
justable rheostat, a current of o.80 amperes - its rated normal load - was passed through the glower. The junction of the thermoelement was then moved slowly up to the incandescent glower. To the writer's surprise the junction could be brought in contact with the glower without melting or being otherwise visibly changed. This was true of the smallest junction used - the radius of which was $0.00360 \mathrm{~cm}$. The only conclusion to be drawn was that the temperature of the incandescent glower was much lower than the early measurements indicated. The radii of the three junctions used were as follows : No. I., had a radius of $0.00592 \mathrm{~cm}$.; No. II., of $0.00493 \mathrm{~cm}$. ; No. III., of $0.00360 \mathrm{~cm}$.

The thermo-electromotive forces generated in these three thermoelements were then measured on the potentiometer - the junction of the thermo-element being meantime in contact with the glower. From a curve, plotted from the values given by Kohlrausch, ${ }^{1}$ the temperature corresponding to each electromotive force was then read and a curve was plotted with corresponding temperatures as ordinates and cross-sections of the wires as abscissæ. In order to eliminate conduction, this curve was extended back until it intersected the axis of ordinates. Thus one eliminated the conduction of the thermo-elements, and obtained at the intersection of the curve with the axis of ordinates, the value of the temperature that would be measured with a wire of zero cross-section. The values obtained from a series of measurements on a half dozen different glowers gave results varying from $1780^{\circ}$ to $1800^{\circ}$ absolute as is shown by the following table :

TABLE II.

Temperatures of Various Glowers as Measured with the Three Thermo-elements.

\begin{tabular}{c|c|c|c|c}
\hline \multirow{2}{*}{ Glower. } & \multicolumn{3}{|c|}{ Temperatures for Elements. } & \multirow{2}{*}{$\begin{array}{c}\text { Exterpolated } \\
\text { Value. }\end{array}$} \\
\cline { 2 - 3 } & No. I. & No. II. & No. III. & \\
\cline { 2 - 3 } I. & $1,223^{\circ}$ & $1,407^{\circ}$ & $1,487^{\circ}$ & $1,505^{\circ} \mathrm{C}$. \\
II. & 1,220 & 1,430 & 1,500 & 1,515 \\
III. & 1,270 & 1,425 & 1,520 & 1,530 \\
IV. & 1,230 & 1,385 & 1,495 & 1,535 \\
V. & 1,145 & 1,320 & 1,460 & 1,510 \\
VI. & 1,150 & $1,330(?)$ & 1,480 & 1,515 \\
\hline
\end{tabular}

1 Kohlrausch, Praktische Physik, p. 157, I90I, $9^{\text {te }}$ Aufl. 
[VoL. XXII.

In some cases the glower was heated by direct current ; in others, by alternating current. Sometimes the glower was in the plane formed by the two wires of the thermo-junction; sometimes the glower was at right angles to the plane including the two wires. In all cases the glower was horizontal. The mean of all these measurements gives a temperature of $179 \mathrm{I}^{\circ}$ absolute.

After making these measurements, in order to make sure that the character of the wires of the thermo-elements had not been changed by contact with the hot oxides constituting the glower, the junctions were used to measure the temperature of various parts of the luminous cone of the Bunsen flame. Values concordant with those obtained by Waggoner ${ }^{1}$ were obtained. Although under a microscope the wires did not present a perfectly smooth appearance like that of a newly drawn wire, yet the tests to which the junctions were subjected made it seem probable that the thermo-junctions used measured the true temperature of the Bunsen flame and of the glowers as accurately as one could expect, considering that there was more or less unavoidable change in the value of the current passing through the glower.

\section{TABle III. (Computed.)}

Watts per Centimeter Length Required by Black Bodies for the Absolute Temperatures Indicated Beloze.

\begin{tabular}{|c|c|c|c|c|c|c|c|}
\hline \multirow{2}{*}{ No. } & \multirow{2}{*}{ Thickness. } & $1700^{\circ}$ & $1800^{\circ}$ & $1900^{\circ}$ & $2000^{\circ}$ & $2100^{\circ}$ & $2200^{\circ}$ \\
\hline & & \multicolumn{6}{|c|}{ Watts per Centimeter. } \\
\hline I. & $0.0290 \mathrm{~cm}$ & 4.10 & 5.11 & 6.35 & 7.81 & 9.50 & 11.44 \\
\hline II. & 0.0618 ، & 8.67 & 10.91 & 13.54 & 16.62 & 20.20 & 24.33 \\
\hline III. & 0.0964 & 13.50 & 17.00 & 21.10 & 26.87 & 31.50 & 37.90 \\
\hline IV. & 0.1000 ، & 14.10 & 17.60 & 22.00 & 27.00 & 32.70 & \\
\hline
\end{tabular}

Some comparisons will now prove of interest. It will be instructive to compare the actual energy supplied to the glower when it is heated to a given temperature, with the energy required to produce the same temperature in a black body of the same dimensions as the Nernst glower. The computed data for the black body are given in Table III. For the absolute temperatures indicated in this table,

1 Waggoner, Wied. Ann., 58, 579, 1896. 
the energy per centimeter length required by a black body of the same cross-section as the Nernst glower is given. In Table I. data showing the energy supplied to four different glowers are given. The first three are German glowers and the accompanying data were obtained by the method first mentioned above, using the Wanner Pyrometer and the iridium furnace to determine the temperature of the glower. The last case, glower No. IV., is one of the American glowers in which case the temperature of the glower was measured by means of the thermo-element. Glowers Nos. III. and IV. of this table are so similar that a comparison is possible. For example, the current strength in the two cases, the watts per centimeter length, the energy per sq. mm., and the candle power per sq. mm., are all of such a relative magnitude as to be comparable. In case of glower No. III., whose temperature was determined by the pyrometer, the temperature was found to be $2300^{\circ}$ absolute. Judging from the candle power per sq. mm., glower No. IV. should be considerably hotter than glower No. III., but with the glower first mentioned the thermo-element showed a temperature of $1800^{\circ}$ absolute. Evidently, therefore, the method used to measure the temperature of No. III. gave values much too high. In other words the laws of Wien and Paschen do not apply to the Nernst glower because it is not a black body, but on the contrary shows̀ selective radiation when compared with the radiation from the latter. These laws cannot be used, therefore, with the constants now available for a black body, in order to determine the temperature of the Nernst glower.

If now we compute the energy lost by glowers Nos. I., II. and III., assuming for the time being that the black body law is followed and that the temperature obtained from measurements based on that law are correct, we find the watts lost per centimeter length to be relatively very small, as is shown by the first part of Table IV. and the percentage loss to be very small, ranging from 5 per cent. to 7 per cent. On the other hand, if we take the temperature obtained by the thermo-element method as the correct temperature of the glower, and then find the energy required to heat a black body of the same dimensions as the glower to the absolute temperature of I $800^{\circ}$ we find a relative large loss, viz., 42 watts, or a percentage loss at $1800^{\circ}$ absolute of 70.5 per cent. 
The advantage from a commercial standpoint of rating the temperature of the Nernst glower above its actual value, is shown very clearly by these figures. From these considerations, it seems quite evident that the economic superiority of the glower over that of a black body is not so great as has been claimed for it. That it is far from being a black body, as has long been known, is also strikingly emphasized. That its true temperature has been placed too high is conclusive. Temperature measurements on the glower based on its radiating power or its photometric qualities, are alike apt to give values which are much too high.

TABLE IV.

Watts per Centimeter Length lost into the Air due to Conduction, Convection, etc.

\begin{tabular}{r|c|c|c}
\hline No. & Absolute Temps. & Watts Lost. & Per Cent. Watts Lost. \\
\cline { 2 - 3 } I. & $2,360^{\circ}$ & 1.01 & 6.2 \\
II. & 2,360 & 4.79 & 7.6 \\
III. & 2,360 & 2.61 & 5.2 \\
IV. & 1,800 & 42.00 & 70.5 \\
\hline
\end{tabular}

